\title{
Gene Expression in Primary Cultured Mouse Hepatocytes with a Cationic Liposomal Vector, TFL-3: Comparison with Rat Hepatocytes
}

\author{
Lap Thi Nguyen, Tatsuhiro Ishida, and Hiroshi KiwadA* \\ Department of Pharmacokinetics and Biopharmaceutics, Faculty of Pharmaceutical Sciences, The University of \\ Tokushima; 1-78-1 Sho-machi, Tokushima 770-8505, Japan. \\ Received February 21, 2005; accepted April 28, 2005; published online May 11, 2005
}

\begin{abstract}
We recently reported that a cationic liposomal vector, TFL-3, could be used to achieve significant gene expression in primary cultured rat hepatocytes (Nguyen et al., Biol. Pharm. Bull., 26, 880-885 (2003)). A combination of hepatocyte transplantation and hepatocyte-targeted gene transfer represents a potentially important strategy for expanding treatment options for liver disease. A widely applied approach to support cross-species is necessary before human applications can be realized. Therefore, in this study, we examined the utility of TFL-3 in another species of rodent hepatocytes, namely mouse hepatocytes. Gene expression in mouse hepatocytes by TFL-3 was successful and the level was higher than those in rat hepatocytes that we recently reported on. Interestingly, it appears that both the degree and rate of gene expression were dependent on the incubation time prior to lipofection as well as on the density of cells per dish, but these parameters were independent of the amount of pDNA associated with the cells. These significantly suggest that the culture time prior to and following lipofection, which are related to the biological condition of the cells, may be one of major factors that affect gene expression in hepatocytes and non- or less dividing cells.
\end{abstract}

Key words gene delivery; cationic liposome; hepatocyte; non-dividing cell; plasmid quantification

The liver is an important target organ for gene therapy, because hepatocytes synthesize a wide variety of proteins, perform a variety of post-translational modifications, and are involved in numerous diseases. Therefore, hepatocyte-targeted gene transfer would represent an important strategy for expanding treatment options for liver diseases. The successful gene expression in mouse hepatocytes in living animals was recently achieved by a rapid injection of a large amount of naked pDNA into a mouse tail vein (the hydrodynamicsbased procedure). ${ }^{1,2)}$ Despite the many desirable features of the procedure such as simplicity, convenience, and high efficiency, this procedure is not suitable for the treatment of liver disease because it seriously damage the hepatocytes. ${ }^{2,3)}$

We recently reported that a cationic liposomal vector, TFL- $3^{4)}$ composed of a cationic lipid, DC-6-14, with helper lipids dioleoylphosphatidylethanolamine and cholesterol ( $1: 0.75: 0.75$ molar ratio), achieved sufficient gene expression in primary cultured rat hepatocytes. ${ }^{5)}$ Hence, TFL-3 may be a suitable vector system for successful gene expression in hepatocytes and it may be an attractive candidate for use in in vivo or ex vivo gene therapy.

Among the currently available therapeutic options, hepatocyte transplantation is a promising procedure that could replace liver transplantation because it would overcome the shortage of available donors as well as a variety of technical difficulties. $^{6-9)}$ Therefore, a combination of hepatocyte transplantation and in vitro hepatocyte-targeted gene transfer using TFL-3, leading to the efficient expression of functional proteins, such as enzymes or growth factors, represent an important strategy for expanding the treatment options for liver disease. However, a widely applied approach to support cross-species is needed before human applications: the utility of TFL-3 on gene expression in non-dividing mammalian cells should be tested with different species. Therefore, in this study, we further examined the utility of TFL-3 on transgene expression in another rodent hepatocyte, namely primary cultured mouse hepatocytes.

\section{MATERIALS AND METHODS}

Materials TFL-3 was a generous gift from Daiichi Pharmaceutical Co. Ltd. (Tokyo, Japan). The pDNA, pGL3- Control, encoding luciferase was purchased from Promega (WI, U.S.A.). Collagenase TYPE I was purchased from Funakoshi (Tokyo, Japan). Cell culture reagents were obtained from Nissui Pharmaceutical Co. Ltd., (Tokyo, Japan). Other reagents were of analytical grade. LipofectAMINE was purchased from Life Technologies (MD, U.S.A.).

Cell Preparation and Culture Parenchymal hepatocytes were isolated from an adult male 4 ddY mouse weighing $17-22 \mathrm{~g}$ (Japan SLC, Shizuoka, Japan) or adult male Wistar rats weighing 170-200g (Japan SLC, Shizuoka, Japan) using the in situ perfusion method, as described earlier. ${ }^{5,10)}$ Animal experiments were evaluated and approved by the Animal and Ethics Review Committee of Faculty of Pharmaceutical Sciences, The University of Tokushima. The isolated hepatocytes were plated at a density of $0.75 \times 10^{6}$ or $1.5 \times 10^{6}$ cells in $60 \mathrm{~mm}$ diameter collagen type I coated dish (IWAKI, Tokyo, Japan), and cultured at $37^{\circ} \mathrm{C}$ under an atmosphere of humidified $5 \% \mathrm{CO}_{2}$ for $4 \mathrm{~h}$ to allow the cells to adhere to the dish. In each preparation, the viability of isolated cells was checked by trypan blue dye exclusion.

Lipofection and Luciferase Assay Lipofection was carried out using procedures as described in our earlier paper. ${ }^{5)}$ Briefly, pDNA/TFL-3 complexes were prepared at a ratio of $3 \mu \mathrm{g}$ of pDNA to $30 \mathrm{nmol}$ of cationic lipid. If necessary, rhodamine-labeled phosphatidylethanolamine $(0.2 \%(\mathrm{~mol} / \mathrm{mol}))$ (Molecular probe, OR, U.S.A.) was incorporated in the liposome as a marker. At 18 or $42 \mathrm{~h}$ following the $4 \mathrm{~h}$ of preculture, the complexes were added to the dish at a final concentration of $1 \mu \mathrm{g} \mathrm{pDNA} / \mathrm{ml}$ of media, which contained $5 \%$ heat-inactivated FBS (lipofection). After a $4 \mathrm{~h}$ lipofection period, the cells were further incubated in complete media for various times until used in the assays.

Luciferase activity was determined by a previously re- 
ported. ${ }^{5)}$ Briefly, the cells were lysed by the addition of $900 \mu \mathrm{l}$ of cell culture lysis reagent (CCLR, Promega). An aliquot of the cell lysate was removed and the luciferase activity determined according to the manufacture's recommended protocol (Promega). The protein content of the lysate was measured with a DC protein assay kit (Bio-Rad Laboratories, CA, U.S.A.) and the data are represented as light counts $/ \mathrm{min} / \mu \mathrm{g}$ of protein.

Measurement of pDNA Delivered in the Hepatocytes The pDNA delivered to hepatocytes was quantitatively determined by using a method recently developed in our laboratory ${ }^{11)}$ with minor modifications. Briefly, at various times post-lipofection, the cells were suspended in $0.5 \mathrm{ml}$ of lysis buffer $(0.5 \%$ Nonidet P-40, $10 \mathrm{~mm}$ Tris, $10 \mathrm{~mm} \mathrm{NaCl}, 3 \mathrm{~mm}$ $\mathrm{MgCl}_{2}, \mathrm{pH}$ 7.4) to destabilize the plasma membrane. Aliquots of the suspension were subjected to PCR study. To extract intracellular DNA (containing pDNA), proteinase K (Merck, Frankfurter, Germany) was added to the fraction to a final concentration of $0.1 \mathrm{mg} / \mathrm{ml}$. After an overnight incubation at $37^{\circ} \mathrm{C}$, proteins were eliminated by phenol/chloroform treatment; and the DNA was precipitated by the addition of ethanol. The precipitate was dissolved in TE buffer $(10 \mathrm{~mm}$ Tris- $\mathrm{HCl}, 1 \mathrm{~mm}$ EDTA ( $\mathrm{pH} 8.0)$ ) and was used as the DNA sample. The concentrations of DNA were determined by measurement of the absorbance at $260 \mathrm{~nm}$ with a Shimadzu UV-1200 spectrophotometer (Shimadzu, Kyoto, Japan).

Part of the luciferase region in the pDNA pGL3 was amplified by PCR (TaKaRa PCR Thermal Cycler (MP TP3000, TAKARA Bio, Shiga, Japan)) with the primers RHY008 (5'GTACACGTTCGTCACATCTC-3') and RHY010(5'-CCTGATACCTGGCAGATGGA-3') (Proligo Japan, Kyoto, Japan). The reaction mixture $(100 \mu \mathrm{l})$ consisted of an adequate amount of template, 100 pmols of primers, $1.6 \mathrm{~mm}$ dNTP, 2.5 units of Taq DNA polymerase (Ex Taq), $1.5 \mathrm{~mm}$ $\mathrm{MgCl}_{2}, 50 \mathrm{~mm} \mathrm{KCl}$ and Tris buffer ( $\mathrm{pH}$ 8.3) (TaKaRa Bio, Shiga, Japan). The PCR was performed by denaturation at $94^{\circ} \mathrm{C}$ for $3 \mathrm{~min}$, followed by 30 cycles at $94^{\circ} \mathrm{C}$ for $1 \mathrm{~min}$, annealing at $55^{\circ} \mathrm{C}$ for $1 \mathrm{~min}$, and extension at $72^{\circ} \mathrm{C}$ for $2 \mathrm{~min}$. After the PCR procedure, a $10 \mu \mathrm{l}$ aliquot of the reaction mixture was subjected to agarose gel (1\%) electrophoresis, and the amplified pDNA was quantified by measuring the fluorescence intensity of ethidium bromide bound to the DNA with an ATTO imaging analyzer (AE-6911) (Tokyo, Japan).

Measurement of TFL-3 Associated with Hepatocytes At various time points post-lipofection, cells were washed twice with $3 \mathrm{ml}$ of cold phosphate-buffered saline (PBS, $\mathrm{pH}$ 7.4) and harvested by the addition of $1 \mathrm{ml}$ of $0.25 \%$ trypsin solution, followed by incubation at $37^{\circ} \mathrm{C}$ for $5 \mathrm{~min}$. The cells were then collected by centrifugation $(1000 \mathrm{rpm}, 5 \mathrm{~min}$, and $4{ }^{\circ} \mathrm{C}$ ). The collected cells were lysed by incubation with $2 \mathrm{ml}$ CCLR at room temperature for $2 \mathrm{~h}$. An aliquot was used for the measurement of rhodamine intensity using a fluorescent spectrophotometer, F-4500 (Hitachi, Tokyo, Japan). The protein content of the sample was determined with the DC protein assay kit. The data are expressed as the amount of liposome (pmol) per $\mu \mathrm{g}$ of protein.

Statistics All values are expressed as the mean \pm S.D. Statistical analyses were performed using the GraphPad InStat software program (GraphPad Software, CA, U.S.A.). The level of significance was set at $p<0.05$.

\section{RESULTS}

Effect of Culture Time Prior to Lipofection on Gene Expression in Primary Cultured Mouse Hepatocytes Mouse hepatocytes were lipofected for $4 \mathrm{~h}$ at either 18 or $42 \mathrm{~h}$ after a $4 \mathrm{~h}$-preculture. Luciferase activity was determined after 24,48 or $72 \mathrm{~h}$ (Fig. 1). Gene expression was gradually increased in a post-lipofection culture time-dependent manner. In addition, the gene expression in cells that had been cultured for a longer period $(42 \mathrm{~h})$ before lipofection was much higher, in total, than in cells cultured for shorter periods $(18 \mathrm{~h})$ before lipofection. Interestingly, gene expression mediated by TFL-3 was much higher (approximately 15 fold) than those mediated by LipofectAMINE. This indicates that TFL-3 is superior to LipofectAMINE in terms of lipofection in primary mouse hepatocytes.

Measurement of pDNA Delivered in and TFL-3 Associated with the Hepatocytes Following a $4 \mathrm{~h}$ lipofection by TFL-3, the amount of pDNA transported into the hepatocytes was quantitatively determined at either $6 \mathrm{~h}$ or $48 \mathrm{~h}$ post-lipofection (Fig. 2A). The successful delivery of pDNA to mouse as well as rat hepatocytes occurred at an earlier time point (6 $\mathrm{h}$ after lipofection). No significant difference in amounts was found between mouse and rat hepatocytes. The amount dramatically decreased for a longer time point $(48 \mathrm{~h}$ after lipofection). It appears that the culture time prior to lipofection has an effect on the retention of transported pDNA (Fig. $2 \mathrm{~A}$, insertion), although this difference would not reflect gene expression, since the restored pDNA was less than $1 \%$ of pDNA delivered at earlier time points.

Under the same experimental conditions, the amount of TFL-3 associated with hepatocytes was also examined (Fig. 2B). There was no significant difference at any of the time points after lipofection. It thus appears that the culture time prior to lipofection has no effect on the amount of TFL-3 bound to the hepatocytes. The amount of bound liposome decreased slightly with increasing time of post-lipofection.

Effect of the Density of Hepatocytes on Lipofection Efficiency A greater gene expression was detected with larger numbers of hepatocytes (Fig. 3). The gene expression for the

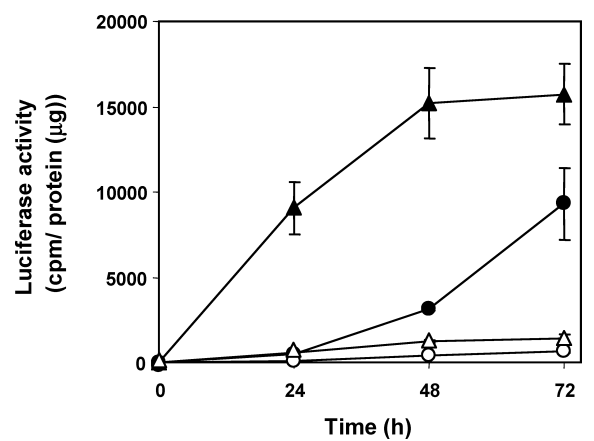

Fig. 1. Effect of Culture Time Prior to Lipofection on Gene Expression in Primary Cultured Mouse Hepatocytes

Isolated mouse hepatocytes $\left(1.5 \times 10^{6}\right.$ cells $)$ were plated in a collagen type-I coated dish $(60 \mathrm{~mm})$ and incubated for $4 \mathrm{~h}$ (preculture). At $18 \mathrm{~h}(\boldsymbol{\bullet}, \bigcirc)$ or $42 \mathrm{~h}(\boldsymbol{\Delta}, \triangle)$ after preculture, the cells were lipofected with either pDNA/TFL-3 complexes (closed symbols) or pDNA/LIPOFECTAMINE complexes (open symbols) for $4 \mathrm{~h}$. After removal of the lipoplexes, the cells were further incubated for periods up to $72 \mathrm{~h}$. During incubation at the indicated time points, the luciferase activity $(\mathrm{cpm} / \mu \mathrm{g}$ of total protein) in hepatocytes was determined as described in the Materials and Methods. The data represent the mean \pm S.D. 

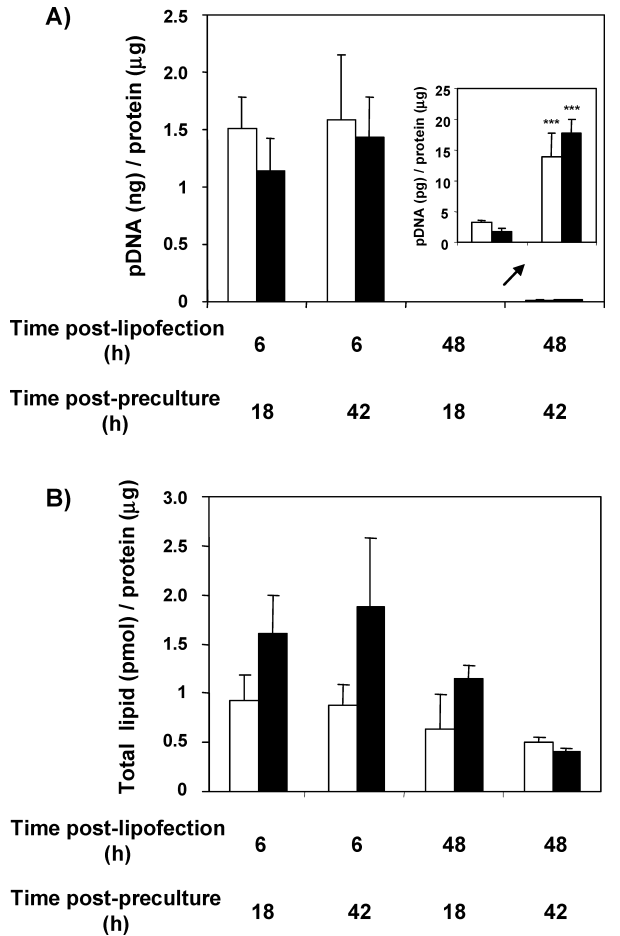

Fig. 2. Amount of pDNA Delivered in and TFL-3 Associated with the Hepatocytes

Isolated mouse $(\square)$ and rat $(\square)$ hepatocytes $\left(1.5 \times 10^{6}\right.$ cells $)$ were plated and incubated for $4 \mathrm{~h}$ (preculture). At $18 \mathrm{~h}$ or $42 \mathrm{~h}$ after preculture, the cells were lipofected for $4 \mathrm{~h}$. At $6 \mathrm{~h}$ or $48 \mathrm{~h}$ post-lipofection, the amounts of pDNA in the cells (A) and TFL-3 bound to the cells (B) were determined as described in the Materials and Methods. The data represent the mean \pm S.D.

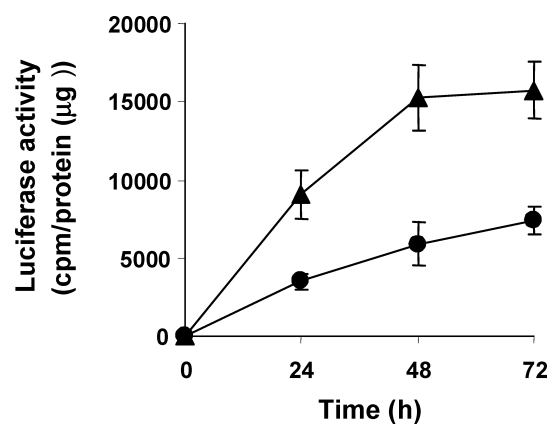

Fig. 3. Effect of Density of Hepatocytes on Lipofection Efficiency

Isolated mouse hepatocytes $\left(0.75 \times 10^{6}(\mathbf{O})\right.$ or $1.5 \times 10^{6}(\boldsymbol{\Delta})$ cells $)$ were plated in a collagen type-I coated dish $(60 \mathrm{~mm})$ and incubated for $4 \mathrm{~h}$ (preculture). At $42 \mathrm{~h}$ after preculture, the cells were lipofected for $4 \mathrm{~h}$. At $6 \mathrm{~h}$ or $48 \mathrm{~h}$ post-lipofection, the amounts of pDNA in the cells and TFL-3 bound to the cells were determined as described in the Materials and Methods. The data represent the mean \pm S.D. After removal of the lipoplexes, the cells were further incubated up to $72 \mathrm{~h}$. During incubation at the indicated time points, luciferase activity $(\mathrm{cpm} / \mu \mathrm{g}$ of total protein) in hepatocytes was determined, as described in the Materials and Methods. The data represent the mean \pm S.D.

case of higher cell density was relatively $2-3$ folds larger that those for the case of a lower cell density. At a higher cell density, gene expression increased, reaching a maximum level up to $48 \mathrm{~h}$. To the contrary, at a lower cell density, gene expression still gradually increased in a culture time postlipofection-dependent manner.

In addition, the viability of hepatocytes was monitored throughout this study. Viability gradually decreased in a culture time-dependent manner with or without lipofection (data not shown), although the efficiency of gene expression relatively increased.

\section{DISCUSSION}

Among the currently available therapeutic options, hepatocyte transplantation is a promising procedure. Therefore, a combination of hepatocyte transplantation and in vitro hepatocyte-targeted gene transfer represents an important strategy for expanding the treatment options for liver disease. TFL-3 may be a candidate for in vitro gene transfer targeted to hepatocytes, since we recently reported that TFL- ${ }^{4)}$ achieved sufficient gene expression in primary cultured rat hepatocytes. ${ }^{5}$ However, a widely applied approach to support cross-species is needed with TFL-3 before human applications. Therefore, in this study, we further examined the utility of TFL-3 on transgene expression in another rodent hepatocyte. If some differences on the gene expression between mouse hepatocytes and rat ones were obtained although both animals are rodent. This would suggest that there is a species difference on the gene expression by hepatocytes.

As a first matter, the issue of whether TFL-3 can be successfully used to achieve gene expression in primary cultured mouse hepatocytes was examined. As shown in Fig. 1, efficient gene expressions could be achieved using TFL3 and the level of gene expression was dependent on the culture time prior to lipofection. In addition, the transgene activity was superior to that of the commercially available LipofectAMINE under our experimental conditions, which is consistent with the result showing the LipofectAMINE does not work very well in the presence of serum. ${ }^{12)}$ These observations are consistent with the result obtained with rat hepatocytes. ${ }^{4)}$ These findings suggest that TFL-3 could be useful vector for achieving a sufficient level of gene expression in rodent hepatocytes.

Interestingly, gene expression in mouse hepatocytes was relatively much higher ( $2-2.5$ fold $)$ than those in the rat hepatocytes. In addition, the peak for maximum gene expression level in mouse hepatocytes appeared to move to a later time point post-lipofection, compared to the results reported for rat hepatocytes. ${ }^{5)}$ This is supported by the report of Weglarz et $a l .^{13,14)}$ demonstrating that the peak for DNA replication after a partial hepatectomy in rats, presumably in hepatocytes, occurs at $24 \mathrm{~h}$ after the operation while it takes place at $44 \mathrm{~h}$ in mice. It appears that the difference in DNA replication is due to the difference in the length of G1 between rat and mouse hepatocytes. ${ }^{15)}$ This suggests that there may be a species difference in exogenous gene expression by the hepatocytes as a result of transfection with TFL-3.

The time of culture prior to lipofection had no effect on the amount of pDNA delivered to rodent hepatocytes (Fig. 2A), while gene expression was obviously dependent on the time of culture prior to lipofection (Fig. 2). ${ }^{5)}$ Similar results have also been reported for other mammalian line cells. ${ }^{16}$ ) These findings suggest that gene expression is not necessarily related to the amount of pDNA delivered by TFL-3, but rather to the biological condition of the hepatocytes that influences, for example, the process of transcription of the delivered pDNA. Of course, the delivery of a sufficient amount of pDNA to the cell and nucleus to permit gene expression is an absolute requisite.

As described in Fig. 3, gene expression increased with increasing cell density. This observation is inconsistent with our earlier results for rat hepatocytes ${ }^{5)}$ and other's. ${ }^{17)}$ This 
discrepancy may be due to differences in experimental conditions; $0.75 \times 10^{6}$ and $1.5 \times 10^{6}$ cells for the mouse study and $1.5 \times 10^{6}$ or $3 \times 10^{6}$ cells for the rat study. ${ }^{5)}$ Gene expression in rat hepatocytes might have already reached the maximum level at a lower cell density $\left(1.5 \times 10^{6}\right)$. Hence, the resulting gene expression may decrease at higher cell density $\left(3.0 \times 10^{6}\right)$. Although the reason for why efficient gene expression was achieved for a lower cell density of hepatocytes is currently unclear, the increased cellular interaction at higher cell density might induce some signal transduction, which would inhibit protein production in the cells. Further study will be required to confirm this assumption.

The results presented here indicate that the conditions used for lipofection are critical for achieving an efficient gene expression in primary cultured hepatocytes. This strongly indicates that an increased gene expression in rodent hepatocytes could be achieved by optimizing the lipofection conditions, such as the time of culture prior to lipofection, the time used for lipofection and the density of the cells. In addition, the results described here and earlier ${ }^{5)}$ demonstrate that the TFL-3 may be a suitable non-viral vector system for successful gene expression in non- or less-dividing cells. Therefore, for developing further efficient delivery system with TFL-3 for clinical use, it will be important to collect more information on the biological conditions that affect the transcription process of target cells.

Acknowledgments We thank Dr. Hiroshi Kikuchi, Daiichi Pharmaceutical, for helpful suggestions and Dr. Milton $\mathrm{S}$. Feather for his helpful advice in writing the English manu- script.

\section{REFERENCES}

1) Zhang G., Budker V., Wolff J. A., Hum. Gene Ther, 10, 1735-1737 (1999).

2) Liu F., Song Y., Liu D., Gene Ther, 6, 1258-1266 (1999).

3) Rossmanith W., Chabicovsky M., Herkner K., Schulte-Hermann R., DNA Cell Biol., 21, 847-853 (2002).

4) Kikuchi A., Aoki Y., Sugaya Y., Serikawa T., Takakuwa K., Tanaka K., Suzuki N., Kikuchi H., Hum. Gene Ther., 10, 947—955 (1999).

5) Nguyen L. T., Ishida T., Ukitsu S., Li W. H., Tachibana R., Kiwada H., Biol. Pharm. Bull., 26, 880-885 (2003).

6) Demetriou A. A., Felcher A., Moscioni A. D., Dig. Dis. Sci., 36 , 1320-1326 (1991).

7) Rhim J. A., Sandgren E. P., Degen J. L., Palmiter R. D., Brinster R. L., Science, 263, 1149-1152 (1994).

8) Wang X., Zhao X., Andersson R., Eur. J. Surg., 161, 475-481 (1995).

9) Vogels B. A., Maas M. A., Bosma A., Chamuleau R. A., Cell Transplant., 5, 369-378 (1996).

10) Tanaka K., Sato M., Tomita Y., Ichihara A., J. Biochem. (Tokyo), 84, 937-946 (1978)

11) Serikawa T., Suzuki N., Kikuchi H., Tanaka K., Kitagawa T., Biochim. Biophys. Acta, 1467, 419-430 (2000).

12) Tachibana R., Harashima H., Shinohara Y., Kiwada H., Adv. Drug Deliv. Rev., 52, 219-226 (2001)

13) Weglarz T. C., Degen J. L., Sandgren E. P., Am. J. Pathol., 157, 1963 1974 (2000).

14) Weglarz T. C., Sandgren E. P., Proc. Natl. Acad. Sci. U.S.A., 97, $12595-12600(2000)$.

15) Fausto N., Campbell J. S., Mech. Dev., 120, 117-130 (2003).

16) Li W., Ishida T., Tachibana R., Almofti M. R., Wang X., Kiwada H., Int. J. Pharm., 276, 67-74 (2004).

17) Watanabe Y., Nomoto H., Takezawa R., Miyoshi N., Akaike T., J. Biochem. (Tokyo), 116, 1220-1226 (1994). 